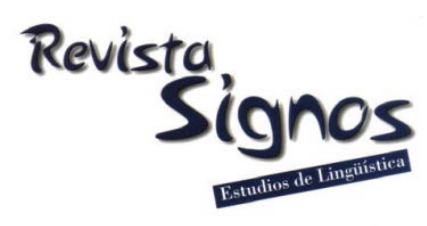

\title{
Linguistic accommodation in online communication: The role of language and gender
}

\author{
Acomodación lingüistica en la comunicación electrónica: El \\ papel de la lengua y el género
}

\author{
Carmen Pérez Sabater \\ UNIVERSITAT POLITĖCNICA DE VALÈnCIA \\ ESPAÑA \\ cperezs@idm.upv.es
}

Recibido: 22-III-2015 / Aceptado: 11-VII-2016

\begin{abstract}
This study forms part of an ongoing line of research that aims to contribute to our understanding of the role of culture and gender in shaping participation in computermediated communication (CMC) environments. The objective of this paper is to determine to what extent female and male participants in online support groups for men and women adapt their linguistic behaviour to that of the other members of the community in their desire for social approval, attractiveness, and integration. By focusing on a diverse sample of adult users of online support groups, we investigate linguistic accommodation at the structural level. Moreover, a comparative discourse analysis between interactions in English and Peninsular Spanish will seek to determine whether this accommodation behaviour, a well-documented phenomenon in English, is common practice in Spanish, where research in the field has not yet been systematically undertaken. In general, the findings show that women converge more to the structure of the forum than men. However, there exist cross-cultural differences in accommodation. The participants writing in Spanish, both men and women, converge more overtly in their use of structural elements than those writing in English. The study on accommodation is complemented by a comparative discourse analysis which reveals that messages posted in women's fora present an intimate, personal, and emotionally expressive linguistic style which favours 'rapport' rather than 'report', a tendency already identified by Tannen (1991) in women's face-to-face conversation.
\end{abstract}

Key Words: Computer-mediated communication (CMC), linguistic accommodation, gender studies, cross-cultural studies, Spanish-English. 


\section{Resumen}

Este estudio forma parte de una investigación en curso centrada en analizar el papel de la cultura y el género en cómo se moldea la participación en la comunicación electrónica. El objetivo de este artículo es determinar en qué medida participantes femeninos y masculinos en grupos de ayuda en línea para hombres y mujeres adaptan su comportamiento lingüístico a los demás miembros de la comunidad buscando aprobación social, gustar a los demás e integración. En un corpus formado por interacciones de adultos en grupos de ayuda se observa acomodación lingüística a nivel estructural. Además, un análisis del discurso comparando interacciones en español peninsular e inglés tratará de determinar si esta acomodación, un fenómeno bien documentado en inglés, es una práctica común en español peninsular, donde no se han realizado investigaciones sistemáticas en este campo. Los resultados muestran que, en general, las mujeres convergen más que los hombres en la estructura del foro de discusión. Sin embargo, existen diferencias interculturales en cuanto a la acomodación. Los participantes en español, tanto hombres como mujeres, convergen más destacadamente en los elementos estructurales que en inglés. El estudio sobre acomodación lingüística se complementa con un análisis del discurso que resalta el estilo íntimo, personal y emocionalmente expresivo de los mensajes escritos por mujeres y que favorece las buenas relaciones en lugar del mero intercambio de información, tendencia ya identificada por Tannen (1991) en las conversaciones cara a cara entre mujeres.

Palabras Clave: Comunicación electrónica, acomodación lingüística, estudios de género, estudios interculturales, español-inglés.

\section{INTRODUCTION}

Accommodation is deeply rooted in human social behaviour (Danescu-NiculescuMizil, Gamon \& Dumais, 2011). Hence, over the last forty years, a wide range of disciplines have approached Speech Accommodation Theory (SAT) and Communication Accommodation Theory (CAT), applying them to several levels of communicative and linguistic analysis. For instance, Giles, Coupland, and Coupland (1991) pointed out that CAT reflects the needs of individual speakers or the members of a group for social integration or identification with another speaker, since similarity is likely to increase a speaker's attractiveness, predictability, and perceived supportiveness, intelligibility, and interpersonal involvement. However, as suggested by Scissors, Gill, Geraghty, and Gergle (2009), online communication occurs in a textbased environment and consequently many of the interpersonal cues through which similarity is established are no longer available. This is the reason why CAT has attracted the attention of Computer-mediated Communication (CMC) scholars. For example, Bunz and Campbell (2004) studied subjects' accommodation to politeness in emails while Danescu-Niculescu-Mizil et al. (2011) investigated Twitter users' convergence to each other's communicative behaviour and demonstrated the robustness of accommodation theory in a large scale empirical analysis. These articles exemplify the recent interest in the role of similarity in language in general and in CMC in particular, although this research has been mostly conducted in the West and 
in English-language settings, with non-Anglophone contexts receiving very little consideration.

In this study, we will see if members of online support groups accommodate their text-based online conversations in environments where no explicit guidelines are imposed on participants, since accommodating to the style of online participants may serve to enhance shared small group identities. Specifically, the study will analyse the relationship between gender, language, and accommodation, factors which may be decisive in explaining greater convergence to the style of other participants in the forum. The purpose of the analysis is twofold. On the one hand, we will see if men and women in online support groups converge in a variety of dimensions.

On the other hand, within the framework of intercultural rhetoric, cross-cultural research or contrastive rhetoric (Connor, Nagelhout \& Rozycki, 2008), this study will also focus on cross-cultural conventions of use in online support groups in order to identify linguistic similarity in text-based conversations in English and Peninsular Spanish. In both approaches, particular attention will be given to linguistic similarity at the structural level. The study of interactions in English and Spanish in online support groups with similar characteristics will seek to determine whether this accommodation behaviour, a well-documented phenomenon in English, is also common practice in Spanish, where research in the field has yet to be systematically undertaken.

In brief, the objective of this investigation is to determine to what extent female and male participants in online support groups for men and women, adapt their linguistic behaviour to that of the other members of the community in their desire for social approval, attractiveness, and integration. By focusing on a diverse sample of adult users of online support groups, we investigate linguistic accommodation at the structural level. Moreover, a comparative discourse analysis between interactions in English and Peninsular Spanish will seek to determine whether this accommodation behaviour is common practice in Spanish.

This study forms part of an ongoing line of research which focuses on the presence of culture and gender differences and similarities in online communication as part of the current academic interest in the discourse of CMC in languages other than English (Pérez-Sabater, Turney \& Montero-Fleta, 2008; Pérez-Tellez, 2015). Crosslinguistic studies have identified similarities and cultural specificities regarding language use online; notwithstanding these studies, more literature in the field is needed, as Lorenzo-Dus and Bou-Franch (2013) claimed. Finally, it must be noted that this study is limited to Peninsular Spanish. This may reduce the relevance of its findings. However, a wider comparison which includes American varieties of Spanish, in addition to Peninsular Spanish and English, is currently beyond the scope of our discussion. 


\section{Theoretical background}

\subsection{Communication Accommodation Theory (CAT)}

Communication Accommodation Theory is a paradigm which has attracted the interest of a wide range of disciplines and has been applied to different media such as writing, songs, and human computer interactions (Giles et al., 1991).

The basic concepts and fundamental strategies of CAT are 'convergence' and 'divergence'. Convergence is:

"the strategy whereby individuals adapt to each other's communicative behaviours in terms of a wide range of linguistic-prosodic-nonverbal features including speech rate, pausal phenomena, and utterance length, phonological variants, smiling, gaze, and so on" (Giles et al., 1991: 7).

Convergent linguistic behaviour indicates greater solidarity and reduced social distance; it is used to achieve social approval or acceptance (Giles \& Ogay, 2006). In contrast, divergence refers to the way in which speakers highlight their speech and nonverbal differences and appear to display reduced solidarity and greater social distance (Scissors et al., 2009). Interestingly, mutual convergence can foster communicative innovations at the lexical, grammatical, prosodic, and nonverbal levels, which may serve to enhance shared couple and family identities as well as emergent small-group identities (Giles et al., 1991).

Gender studies on accommodation have identified differences in the way males and females adapt their discourse to their partners'. For instance, Mulac, Studley, Widenmann, and Bradac (1987) found that women converged more than men toward their partners' gaze in mixed-sex dyadic environments. In CMC, accommodation has attracted the attention of scholars such as Crystal (2001:147) who reported that in chat groups and virtual worlds members accommodate to each other so that they progressively develop "a shared linguistic character - the equivalent of a local dialect or accent" even though they come from different backgrounds and have varied writing styles. Bunz and Campbell (2004) studied the important role played by greetings and farewells in setting the tone of email interactions. They examined how structural politeness markers, such as explicit greetings and closings, and verbal politeness markers, such as 'please' and 'thank you', influence the extent to which individuals accommodate to politeness markers. Thomson and Murachver (2001) examined the role of CAT in men's and women's email communication styles. They concluded that men and women were equally likely to ask questions, offer compliments, apologies, and opinions, as well as insult their interlocutors. Similarly, Fox, Bukatko, Hallahan and Crawford (2007) found that men and women used more references to emotion when the Instant Message was directed to women. In their study of Instant Messaging, Scissors et al. (2009) investigated how different forms of 
'linguistic similarity' grounded in CAT relate to the establishment of personal trust. In their view, linguistic similarity can occur at three levels: the content level or emotion and task-related content; the structural level, which can be measured, for example, in terms of verb tense use; and the stylistic level, for example, the use of the same jargon as a communicative partner to express affinity. The work of Riordan, Markman, and Stewart (2013) has also studied communication accommodation in Instant Messaging. Their conclusions suggest that interlocutors have a general tendency towards convergence in the length and duration of individual contributions. Their results also show that the context of the exchange produces different levels of convergence. Despite these findings, most of them within the field of Computing, Psychology or Sociology, researchers such as Fox et al. (2007) suggest that more research on CAT and online genres is needed to understand how, when, and why.

\subsection{Online support groups}

'Communities of practice' appear as groups of people respond to a mutual situation; participants come together because they have a shared interest in a particular time and place (Eckert \& McConnell-Ginet, 2013). Within these communities of practice, support groups provide comfort to participants and make them feel better; they are an effective vehicle for obtaining help (Barak, Boniel-Nissim \& Suler, 2008). They may operate without a leader or manager because they are mainly based on the premise that people who share similar problems can understand each other better than those who do not. Support groups can also increase solidarity among their members as well as their physical well-being (White \& Dorman, 2001). Moreover, online support groups offer specific added value: anonymity and invisibility (Barak et al., 2008). Anonymity allows participants to feel less vulnerable and to open up with greater ease because their comments remain within the forum and cannot be linked to the rest of their lives. Meanwhile, invisibility further disinhibits participant behaviour because posters do not have to worry about how they look or sound. This is particularly important in groups that address physical or speech problems, as Barak et al. (2008) indicated. Interestingly, in the opinion of Davison, Pennebaker and Dickerson (2000), online support groups are a milieu where potent social factors are neutralised. Among these factors, gender, power, and status are particularly relevant because in these fora, " ...everyone, regardless of status, wealth, race, or gender, starts off on a level playing field" (Barak et al., 2008: 1872). Therefore, online support groups could be the perfect arena for investigations into how participants accommodate their text-based interactions, often unconsciously, to converge towards the other members of the group and integrate into the online community.

Linguistically, these for a have some common and relevant characteristics. Among these is the finding that participants must utilize less complex language to increase the likelihood of receiving a response. According to Arguello, Butler, Joyce, Kraut, Ling, 
Rosé and Wang (2006), receiving a response is a crucial factor in determining the engagement of Internet support group participants in online communities. In their opinion, it is important to avoid writing long posts and long sentences (Arguello et al., 2006). Another interesting factor is the paramount role of word choice, since words undoubtedly reflect the writer's attitudes towards the online community. For instance, first person pronouns such as 'we' and 'us' express solidarity with the group, while third person pronouns may distinguish between 'in-group' and 'out-group' participation (Arguello et al., 2006).

Receiving a response has other interesting implications. Arguello et al. (2006) suggest it enhances community membership, an important factor in health support groups because newcomers are more likely to engage in the online community if their questions are answered. To receive a response, members include testimonials or requests, self-references with first person pronouns, descriptions of cognitive states and processes, and expressions of positive or negative emotions (Arguello et al., 2006). These rhetorical strategies may serve to allow users to benefit from and contribute to online communities.

\subsection{Online support groups and gender studies}

Researchers such as Davison et al. (2000) have contended that online support groups are a milieu, where potent social factors including gender are neutralised. Indeed, many studies in various fields have sought to demonstrate that online communities do neutralise gender differences by providing participants with an arena in which they can engage in behaviours that deviate from stereotypical gender norms. The literature review on this topic by Mo, Malik and Coulson (2009) concludes that gender-specific preferences and behaviours can be identified in male-only and femaleonly online support groups for cancer. Research has confirmed that females prefer support groups that discuss emotional issues while males prefer information-oriented support groups (Seale, Ziebland \& Charteris-Black, 2006). Gender differences in language use in online support groups have been identified by Seale et al. (2006). They reported that women in breast cancer communities used more words associated with support, feelings and people, and superlative forms that exhibit greater emotional expressivity. In contrast, the keywords used by men in prostate cancer support groups denoted awareness, information, and choice; the men deployed more words than women concerning the disease and its progression.

Notwithstanding the aforementioned studies, most of which analyse online communities which support cancer patients, Mo et al. (2009) stress the need for a systematic analysis of more online support groups to enable the development of effective online support group interventions, in their case, by health care professionals. This article describes an analysis of online support groups for physical changes and disorders which are closely connected to gender and sexuality: Online 
support groups for menopause and erectile dysfunction. The relevance of this study stems from the fact that there is hardly any systematic research published on online support group interaction in the field of contrastive English-Spanish studies. This research could therefore contribute "to the development of a body of socio-culturally sensitive research on cross-cultural computer-mediated communication" (LorenzoDus \& Bou-Franch, 2013: 19).

\section{Research questions and scope of the study}

Accommodation is often related to social attractiveness, solidarity, and trust (see, for example, Giles et al., 1991; Scissors et al., 2009). It is a reflection of the desire for social approval, attractiveness and integration (Giles et al., 1991). In brief, it is what posters to online support groups demand from their online communities.

The objective of this paper is to determine to what extent female and male participants in online support groups for men and women adapt their linguistic behaviour to that of the other members of the community in their desire for social approval, attractiveness and integration. Accommodation will be studied at the content and structural level using CAT, as described by Scissors et al. (2009).

Thus, the research questions of this study will be:

1. In online support groups, without imposing explicit guidelines on participants, do men and women accommodate their style by converging to structural elements?

2. Does the language used and its associated culture influence linguistic similarity at the structural level?

A final consideration regarding these research questions and the three levels of analysis suggested by Scissors et al. (2009) requires clarification. In online support groups, the content of messages necessarily refers to the forum's topic. An initial and brief observation of our corpus led to the decision to discard the content variable since all the posts analysed were on topic. Therefore, topic drift and the distinction between 'on-topic' and 'off-topic' posts were not taken into account in this study. Posters to online support groups know that off-topic posts are not answered and may be deleted by webmasters or moderators; they can be treated as "undesirable noise that fails to contribute to the group and may even distract other members" (Arguello et al., 2006: 3). On the other hand, an analysis of linguistic similarity at the stylistic level cannot be carried out at this time because the author is unable to provide appropriate statistical procedures to demonstrate intragroup stylistic accommodation/convergence. Such procedures would require the participation of more researchers, see, for example, Scissors et al. (2009) on linguistic similarity at the stylistic level or Pérez-Tellez, Cardiff, Rosso and Pinto (2015) on semantic similarity. 
Therefore, we leave analysis of intergroup and intragroup linguistic similarity at the stylistic level for future research.

\section{Method}

\subsection{Corpus studied}

The corpus of electronic fora devoted to menopause and erectile dysfunction problems will be analysed following the Computer-mediated Discourse Analysis (CMDA) approach described by Herring (2004). Consequently, the main focus of this CMDA is linguistic accommodation, together with other issues such as gender relations and contrastive English-Spanish analysis. Statistics and a corpus analyser together with some detailed descriptions of exemplary texts are also used.

Traditionally, research into accommodation in online support groups has studied gender differences by investigating breast and prostate cancer communities. The aim of the research presented in this article is to investigate gender-specific issues in online communities while avoiding the traditional route. The decision was made to analyse menopause and erectile dysfunction groups, online support groups for physical changes and sufferings that are closely interconnected with gender and sexuality. The convenience sample examined was selected because it was easy to access, although it should be noted that it was very difficult to select fora that address these topics: only those that were dynamic (i.e. with highly active and recent interaction) and serious (i.e. with no hidden commercial purposes) were considered to be of scholarly interest. Moreover, for ethical reasons, only those fora which are publicly displayed were selected. Fora also had to be hosted on websites with links to other communication platforms such as Facebook and Twitter, as future research may involve messages posted on these platforms. Instead of selecting only one forum from each of the menopause or erectile dysfunction categories, two fora were chosen to enlarge the scope of the analysis through the study of several communities of practice with similar interests but hosted by different organizations.

\subsubsection{Corpora in English}

A) Corpus by men:

1) 4,000 words posted to a forum hosted by the National Health Service (NHS) on erectile dysfunction. In this forum, men can share their worries and support is provided either by other participants or by medical staff: http://www.nhs.uk/conditions/erectile-dysfunction/pages/introduction.aspx

2) 4,000 words downloaded from an online medical resource which supplies evidencebased information on a wide range of medical and health topics to patients and health professionals. These posts were written in the forum about erectile dysfunction at: http://www.patient.co.uk/forums/discuss/browse/penis-disorders-3405 
B) Corpus by women:

1) 4,000 words from a forum hosted by the NHS on menopause that tries to help women cope with it. On this website, women can express their worries by leaving a comment which can be answered by a professional or by any participant in the thread: http://www.nhs.uk/conditions/menopause.

2) 4,000 words downloaded from Mumsnet, a forum recommended by the NHS where women can talk to other women. It has several threads on health topics. Similar to the Spanish forum below, the thread on early menopause was chosen because the comments posted may reflect more intensely the emotional and physical changes suffered during menopause, such as anxiety and despair: http://www.mumsnet.com/Talk/menopause?nhs_choices=1.

\subsubsection{Corpora in Spanish}

Some previous considerations need to be addressed concerning the formation of the corpus in Spanish. Only comments posted by writers using Peninsular Spanish were downloaded. The inclusion of different varieties of Spanish would mean additional variables that would have to be included in the study, especially the geographical variation in social deixis in Latin America since pronoun use is a decisive parameter in the study.

A) Corpus by men:

1) 4,000 words from comments posted to an online help website that deals with sexual problems. It has several threads where participants can ask for the help of a professional on different topics. This website provides free online help or face-to-face professional advice in their clinic: http://www.consultasexologo.com/asesoramiento_gratuito.

2) 4,000 words from a forum where posters can be answered by a professional or by other registered members. This website is run by a famous Spanish scientist and financed by a foundation. In addition to erectile dysfunction, it also deals with other topics of interest: http://www.fundacionpunset.org/apol/13849/manejo-de-ladisfuncion-erectil-psicologica/.

B) Corpus by women:

1) 4,000 words from comments posted to the Spanish Association for the Study of Menopause, a non-profit organization of professionals whose members work in different specialist areas such as gynaecology, rheumatology, endocrinology, primary attention and nursing. It was founded by doctors in order to studying the menopause. 
It includes several tools such as Twitter, Facebook and an online forum where doctors answer questions posed by women: http://www.aeem.es/responde.asp

2) 4,000 words from comments posted in a forum where women respond to other women in a thread about early menopause problems (Diario Femenino: http://www.diariofemenino.com/). This is an online women's magazine that has several subsections such as fashion, celebrities, health, and beauty. On this website, people can participate in their specialised fora and online media such as Facebook, Twitter or Google+.

The rules or conventions of use of the fora are similar: posters to fora founded by official institutions are seeking advice from a professional, and this is their principal objective when writing in the thread. On the other hand, posters to non-official sites seek to exchange experiences with members with the same problems. The target population of the latter is other men or women with similar profiles. In all the fora, webmasters, administrators or moderators have an active presence, supervising the fair exchange of messages and removing any offensive content.

The sample includes no more than one comment from the same participant to provide a wider representation of the population interacting online. The selection criteria did not consider whether the posters were newcomers to the thread or not, since this can be difficult to determine. There are no written rules regarding the content, structure or style of the post in any of the groups studied. It is important to note that the 4,000 words per forum correspond to a different number of posts as the length of posts varies depending on the author and the forum (for example, 4,000 words correspond to 36 posts from the NHS erectile dysfunction forum and 42 from Diario femenino). Although interesting, this study does not address post, word or paragraph length as has been the case in previous studies by the author. The study of these parameters has been fruitful in the past and could be of academic interest in the future, but will remain outside the scope of our present discussion.

Table 1. Summarises the content of the corpus analysed.

\begin{tabular}{|l|l|l|l|l|}
\hline & \multicolumn{2}{|c|}{ English } & \multicolumn{2}{c|}{ Spanish } \\
\hline Erectile dysfunction & NHS & Patient & $\begin{array}{l}\text { Consultas } \\
\text { sexólogo }\end{array}$ & $\begin{array}{l}\text { Disfunción } \\
\text { eréctil }\end{array}$ \\
\hline Menopause & NHS & Mumset & $\begin{array}{l}\text { Asociación } \\
\text { menopausia }\end{array}$ & $\begin{array}{l}\text { Diario } \\
\text { femenino }\end{array}$ \\
\hline
\end{tabular}

\subsection{Procedure and parameters}

Public comments posted in the eight fora described above were downloaded. Then a balanced number of words were randomly selected from each corpus. 
In order to establish differences between the sexes (in people speaking the same language) and differences between languages (in people of the same sex), we created some contingency tables. We used Pearson's chi-squared test and we selected the level for statistical significance at $\alpha=0.05$. Reliability was established by two raters who independently coded each corpus using CAT, following the parameters outlined by Scissors et al. (2009).

Linguistic similarity at the structural level was measured in terms of a similar use of verb tense (Scissors et al., 2009) or, as Bunz and Campbell (2004) suggest, measured by converging to structural elements such as salutation and closing remarks. In this study, full similarity was considered to occur when the message followed the following pattern: initial greetings and age, symptoms, effect of treatment, current situation plus uncertainty about health situation, request for advice, and some sort of farewell. As the common structure in all the groups studied, Example 1, a post from Mumsnet, could broadly exemplify this model:

(1) Message posted to a forum in English ${ }^{1}$.

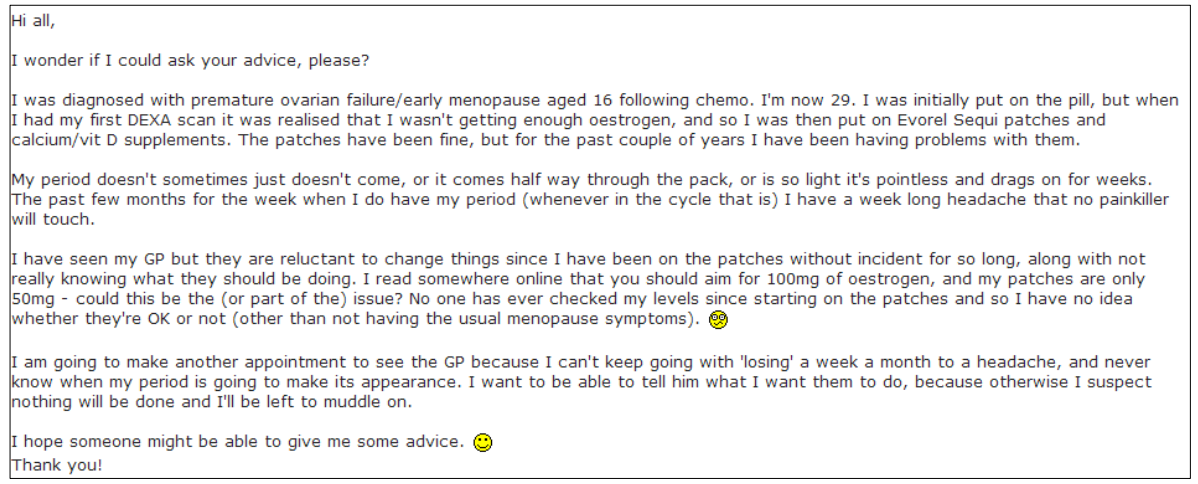

Partial similarity occurred when the post had either no salutation or sign-off but otherwise followed the model shown in Example 1. The rest of the posts that did not comply with the model were consigned to a third category: 'on-topic but no model followed'.

Moreover, following Herring (2004), a comparative discourse analysis of the comments was undertaken to supplement the study on accommodation. Cultural differences were identified by examining the discourse style of these comments. As mentioned in the literature review, researchers have identified some common linguistic characteristics of messages posted in online support groups. Among these, we will focus on word choice and the use of pronouns (Arguello et al., 2006; Seale et al., 2006). The detailed manual examination of the written exchanges was complemented by the corpus analyser $W$ ord $S$ mith, which could provide the study with more insightful details. 


\section{Results}

The manual and automated analyses identified linguistic similarity at the content and structural levels. The results show that, in general, with the exception of a group in Spanish that will be discussed below, women converge to the model much more than men. The cross-cultural results demonstrate that posters in Spanish present higher levels of accommodation in structure than posters in English.

Tables 2 and 3 display the results categorised by gender and language used.

Table 2. Percentage of similarity at the structural level in English.

\begin{tabular}{|l|c|c|c|c|}
\hline \multirow{2}{*}{ Linguistic similarity at the structural level } & \multicolumn{4}{|c|}{ English } \\
\cline { 2 - 5 } & \multicolumn{2}{|c|}{ Men } & \multicolumn{2}{c|}{ Women } \\
\cline { 2 - 5 } & NHS & Patient & NHS & Mumsnet \\
\hline Full similarity & $9 \%$ & $13.3 \%$ & $21.4 \%$ & $14.3 \%$ \\
\hline Partial similarity & $30.8 \%$ & $26.7 \%$ & $71.4 \%$ & $50 \%$ \\
\hline On-topic but no model followed & $60.2 \%$ & $60 \%$ & $7.1 \%$ & $35.7 \%$ \\
\hline
\end{tabular}

Table 3. Percentage of similarity at the structural level in Spanish.

\begin{tabular}{|l|c|c|c|c|}
\hline \multirow{2}{*}{$\begin{array}{c}\text { Linguistic similarity at } \\
\text { the structural level }\end{array}$} & \multicolumn{3}{|c|}{ Men } & \multicolumn{2}{c|}{ Women } \\
\cline { 2 - 5 } & $\begin{array}{c}\text { Consulta } \\
\text { sexólogo }\end{array}$ & $\begin{array}{c}\text { Disfunción } \\
\text { eréctil }\end{array}$ & $\begin{array}{c}\text { Asociación } \\
\text { menopausia }\end{array}$ & $\begin{array}{c}\text { Diario } \\
\text { femenino }\end{array}$ \\
\hline Full similarity & $71.4 \%$ & $46.1 \%$ & $47.6 \%$ & $36.8 \%$ \\
\hline Partial similarity & $14.3 \%$ & $30.8 \%$ & $47.6 \%$ & $57.9 \%$ \\
\hline $\begin{array}{l}\text { On-topic but no model } \\
\text { followed }\end{array}$ & $14.3 \%$ & $23.1 \%$ & $4.8 \%$ & $5.3 \%$ \\
\hline
\end{tabular}

We created contingency tables to analyse the differences between sex and/or language. As an example, Table 4 shows the contingency table devised to compare the messages written by women and men who speak Spanish. In this case, the p-value was lower than 0.001, which indicates that there is significant difference between the linguistic similarity at the structural level in the messages written by men and women.

Table 4. Contingency table of linguistic similarity at the structural level in the fora for Spanish speakers.

\begin{tabular}{|l|c|c|}
\cline { 2 - 3 } \multicolumn{1}{c|}{} & Men & Women \\
\hline Full similarity & 4,700 & 3,376 \\
\hline Partial similarity & 1,804 & 4,208 \\
\hline On-topic but no model followed & 1,496 & 404 \\
\hline
\end{tabular}

We omit the other contingency tables to avoid repetition. Nevertheless, all the tables contain p-values lower than 0.001. This confirms that there are significant differences between the messages posted by men and women who speak English, 
differences between Spanish and English male speakers, and differences between languages in these women's fora.

A detailed analysis of the results reveals that, in general, the users of the English fora are less systematic in the organisation of their posts: most messages are only partially similar with no greetings or farewells, and when such salutations are included, especially in the women's fora, they are imaginative, humorous, and contain many emoticons. Example 1 from the NHS erectile dysfunction forum exemplifies how posts in English in men's fora usually go straight to the point; we rarely find a salutation or greeting:

(1) Introductory sentence from the NHS forum for erectile dysfunction.

"I had a vasectomy in 2003. From that day forward I have never had an orgasm ..."

We often find no salutations in posts in English in women's fora, as in Example 2:

(2) First line of a post in the NHS forum for menopause.

"I am 47 and have been in the peri menapause for what feels like a long ..."

However, when we do find introductory sentences, they usually include imaginative wordplay, humour, emoticons and pictures, as these examples show:

(3) Imaginative salutation in Mumsnet.

Thought I might look in here... I bring $q$ and

(4) Example of a salutation from Mumsnet.

"I might be joining you ladies.

In contrast, salutations are often included in posts in Spanish.

(5) Introduction of a post to Consulta sexólogo.

"Hola! Tengo 35 años y nunca he tenido una relación sexual completa. [Hello! I am 35 and I have never had full sexual intercourse.]"

(6) Initial sentence from Diario femenino.

"Hola tengo 40 años hace casi dos años ... [Hello I am 40 nearly two years ago ...]"

Of particular interest is a salutation frequently used in the fora by men. In both corpora by men, we habitually find a salutation generally used in Peninsular Spanish when entering a place physically: Buenas [good]. Here there is ellipsis of the second part of the salutation 'good morning' or 'good evening', as in Example 7:

(7) Salutation in Disfunción eréctil.

"Buenas,

Me llamo Alfonso ... [Good ..., my name is Alfonso]" 
On the other hand, sign-offs usually include some kind of request and/or politeness indicator. For instance, in English men's fora, we find that most farewells imply a desperate need for help, as the following example illustrates:

(8) Farewell from the NHS forum for erectile dysfunction.

“... as I can't give her the satisfaction she desires through penetrative sex. Please Help!!!”

In women's fora in English, sign-offs usually consist in questions posed to the thread, as in these examples:

(9) Final sentence in the women's forum from Mumsnet.

"Anyone else out there having similar issues?"

(10) NHS for menopause sign-off.

"Could I be menopausal??"

In Spanish, most posts written by both males and females have a politeness indicator of the type 'thank you' or 'thanks a lot' as a closing remark. Examples 12 and 13 show this similarity at the structural level and are also representative examples of the general linguistic style of messages in the four Spanish fora:

(11) Closing from Disfunción eréctil.

"No sé qué hacer. Gracias de antemano. [I do not know what to do. Thanks in advance]"

(12) Closing from Consulta sexólogo.

“... mas estres, tensión y nervios.

Muchas gracias por su respuesta. [more stress, tension, and nerves. Many thanks for your answer]"

(13) Closing sentence from Asociación menopausia.

"A ver si pueden ayudarme, muchas gracias! [Let's see if you can help me, many thanks!]"

When considering the linguistic style of the fora, the study of self-mentions is one point of departure. Self-mentions, which include the use of first person singular and plural pronouns, clearly depend on the cultural context where a text is performed and distributed (Mur-Dueñas, 2007). The findings indicate two tendencies in the use of singular and plural pronouns. In the singular, in both cultural contexts, we find comparable pronoun usage. In this way our findings differ from other cross-cultural studies on the utilisation of first person subject and object pronouns, and possessive adjectives and possessive pronouns (Mur-Dueñas, 2007). The analysis of our corpus using WordSmith software confirms that in the English fora ' $\mathrm{I}$ ' is the most frequentlyused word, a clear marker of writer involvement in the text. Likewise, the first person of the verb 'to have' in Spanish (tengo) is one of the most commonly-used words in the fora. In Spanish the subject pronouns are usually omitted, therefore the comparison 
between ' $\mathrm{I}$ ' and Spanish first person verb forms is valid as they can be functionally equivalent, as Mur-Dueñas (2007) posited. Moreover, in both languages, the use of the first person object pronoun 'me' in English and me in Spanish are both ranked in very high positions on the frequency lists.

Regarding pronouns in the plural, the use of first person forms such as 'we' and 'us' in online communities may express solidarity with the support group (Arguello et al., 2006). The lexical analysis of this corpus evidences that in English, however, first person plural forms rank low on the frequency list in both genders: 'we' at position 150 and 'us' at 901 out of a total of 1,927. In Spanish, by contrast, and especially in women's groups, we find the possessive nos, an inclusive engagement marker, in very remarkable positions, at position number 70 out a total of 2,138 words on the frequency list. This may corroborate the findings of other cross-cultural studies which suggest that Spanish nationals use the Spanish language in positive politeness-oriented ways which emphasises in-group involvement and relations (Mur-Dueñas, 2007; Lorenzo-Dus \& Bou-Franch, 2013).

Lexical politeness is reflected in the frequency list results which confirm that both men and women employed 'thank you' extensively in Spanish. In fact, gracias occupies the $31^{\text {st }}$ position on the frequency list for women's fora and $33^{\text {rd }}$ on the men's, whereas in English 'thanks' or any other thanking formulae do not occupy any of the first 50 positions on the frequency lists for the English fora.

A final consideration is the fact that in the English fora for women wordplay and humour does not only occur in salutations and farewells, as in the examples seen above. Rather, this humorous style is also detected in some nicks that involve imaginative wordplay and fun such as 'Misfitless'. This is not the case in Spanish where there is no humorous wordplay. Nevertheless, while the detailed study of nicknames is interesting, it is not the aim of this research.

Lastly, we must discuss addressivity, a factor that may enhance accommodation at the structural level. Addressivity (Werry, 1996), whereby a message is prefaced by the nickname of the intended addressee, is important in online fora and social media such as Twitter to clarify to whom the message is addressed. For instance, in Twitter addressivity is performed by the inclusion of @ , a convention to address a post to a particular user (Danescu-Niculescu-Mizil et al., 2011) which markedly reinforces the conversational style of online writing (Honeycutt \& Herring, 2009). In the fora studied, and especially in the support groups not run by official institutions, there is some addressivity both in English and Spanish because participants need to clarify to whom the advice in their message is directed. The percentage of messages addressed to one participant in men's fora is not significant: only $2 \%$ of the messages include the name of the intended addressee. However, in women's fora there is some addressivity because it seems participants need to clarify to whom their message is directed, 
although the percentage of messages related to one particular participant is not very high: $26 \%$ in Mumsnet and 23.8\% in Diario femenino. Only $7 \%$ of the messages in the NHS forum are directed to a specific member of the online community. There is no addressivity in the Spanish forum of the Asociacion menopausia because all the messages are submitted to be answered by doctors.

\section{Discussion}

As in face-to-face conversations, scholars have determined that participants in online conversation adapt their linguistic behaviour to that of their partners'. With regard to the first research question of this study, the results show that, in general, women accommodate to the general structure of the online community to a greater extent than men. Thus, females' greater convergence to the general style of the forum may reflect their need to be socially involved in the support community, since adaptation is done mainly to demonstrate that speakers are socially receptive and accommodating, as Scissors et al. (2009) contend. This accommodation may have an even greater role in online support groups because participants need comfort, advice, and solidarity (Ferrara, 1991). The findings of this analysis confirm those of previous research which demonstrated that men and women are likely to use online support groups differently. These previous studies concluded that while men interact in online support groups to exchange information, women use them to share experiences, give encouragement and receive support (White \& Dorman, 2001).

With regard to cultural differences in online interactions, Orgad (2006: 890) found that although online support groups seem to provide services that transcend national and cultural borders, "cultures and national contexts continue to play a central role in the shaping of the Internet and CMC". The findings of our research appear to support Orgad's results (2006). In response to our second research question, the results of the cross-cultural study imply that there is a clear tendency towards convergence in Spanish. The greater similarity at the structural level observed in online discussions in Spanish implies that the online writers of this corpus adapt to the general structure of the support groups. They accommodate to a greater extent to the general structure of the fora and converge more visibly in their use of structural elements than the writers using English. This tendency has been corroborated by other studies which investigated the use of greetings and closings. Oliveira (2013) suggests that the degree to which the use of address forms is expected is culturally determined; for example, while in English the omission of a greeting may go unnoticed by the online community, in other languages this omission may be cause for comment. This is the case in Spanish and the reason why the interactants almost always introduce a salutation in their posts, a tendency already noted by Lorenzo-Dus and Bou-Franch (2013). The case of men converging to such a great extent in the forum Consultas sexólogo needs to be studied further. However, this convergence seems to suggest that 
participants maintain their distance from others and feel more secure by following the inherent structure of the forum faithfully.

We can also highlight some interesting findings with regard to the linguistic style of these comments. One notable finding is pronoun use. As Arguello et al. (2006: 3) claimed, an important linguistic factor in online support groups is the use of first person plural pronouns because "first person plural pronouns such as 'we' and 'us' may express solidarity with the group". However, the cross-cultural study shows that this use is only remarkable in the women's fora in Spanish. The significant role of the inclusive first person plural in women's fora in Spanish is a clear strategy to reinforce the sense of online community. Its use helps corroborate our previous statement: Spanish is a positively politeness-oriented culture which emphasises in-group involvement and relations.

Interestingly, the findings bring to the fore the impact of humour in these fora. Traditionally, and as Lakoff (2004) has remarked, women are said to have no sense of humour. In online discussion groups, scholars such as Guiller and Durndell (2006) have identified more instances of humour in men's participation in online discussion groups. In their study, more males than females sent messages containing humour. This is in stark contrast to the findings of this study with regard to messages in English: women utilise wordplay and humour while in men's erectile dysfunction groups there is a complete absence of humorous wordplay. It seems that the traditional assumption that women have no sense of humour is somehow overturned in online support groups. Indeed, studies such as Orgad's (2006) found similar wordplay and humour in online support groups for breast cancer. In Orgad's research, US women adopted a cheerful and triumphant attitude despite suffering painful and difficult experiences; only one person in the community was critical of this cheerful attitude: a non-American interviewee. The use of humour in women's interactions is a strategy of positive politeness. Indeed, the communicative intention of humour in these fora seems to be a method of strengthening the sense of community and shared values, as defined by Brown and Levinson (1987). With regard to his issue, Colley, Todd, Bland, Holmes, Khanom and Pike (2004) posited that humour is used more by females in emails written to other females because it is a strategy to reinforce relational identity and a way of sharing and accommodating to the friend's gender, closeness or both.

This leads us to consider the absence of wordplay and humour in the messages in Spanish. These results are in line with those obtained by Montero-Fleta, MontesinosLópez, Pérez-Sabater and Turney (2009) in a contrastive study among fora in several languages. In their study, Montero et al. (2009) posited that online writers using Spanish seem to concord with Machin and van Leeuwen's (2007) idea regarding the existence of 'well-patrolled boundaries' in discourse practices in Spanish and the 
reluctance to mix information and entertainment, an idea which has been overtly corroborated in this study. It appears that Spanish speakers broadly follow the general style of the fora, in these cases, support groups where participants are in pain and where humour and wordplay are not appropriate. Writers using Spanish, and nonnative speakers of English, as in the study of Orgad (2006), are therefore reluctant to mix linguistic styles.

In light of the above and as a final comment on the results, we can refer to Eckert and McConell-Ginet (2013: 46), who established that participants in communities of practice associate the desire to belong to the groups with "a desire to establish similarity with others - a desire to conform". In this corpus, the desire to develop common knowledge and beliefs is more deeply-rooted in women's interactions and those conducted in Spanish by both genders.

\section{CONCLUSIONS}

In general, the results from the interactions in these communities of practice are in line with those reported in previous literature in the field: Women converge more than men and use more similar linguistic styles. The language practices of women in these groups tend inescapably towards homogenisation rather than diversification, a tendency which enhances the sociability of these exchanges and provides the necessary conventions of use to belong to a particular speech community. However, there are cross-cultural differences in accommodation. The participants using Spanish, both men and women, accommodate to the general style of the forum and converge more overtly in their use of structural elements than the participants using English. They seem to exhibit a greater feeling of belonging to the group, abiding more closely to the non-written rules of community behaviour.

Another interesting issue to note is that the messages in the women's fora present an intimate, personal, and emotionally expressive linguistic style which favours 'rapport' rather than 'report', a tendency already identified by Tannen (1991) in women's face-to-face conversation. Nevertheless, this tendency is expressed differently in English and Spanish. In English we find humour and wordplay as a strategy to reinforce relational identity; in Spanish we observe more accommodation at the structural level and the notable role of inclusive first person plural forms.

Indeed, the conclusions of this study demonstrate that the Internet markedly reflects the society in which it is embedded, one in which men and women conform to deeply-rooted cultural patterns. These conclusions are similar to those drawn by Herring and Stoerger (2014) in their study of gender and CMC.

I would like to finish this article by sharing the words of Danescu et al. (2011) who indicated that their study, like this one, 'merely scratches the surface of this potentially rich discussion of the need to expand the concept of new media literacy'. Other 
studies will be needed to investigate the new discourse practices of online communication in depth, especially in non-Anglophone fora. Further research could also overcome the limitations of this study by comparing American varieties of Spanish to Peninsular Spanish and English. Such studies may address how the Spanish varieties in close contact with English are influenced by this language for geographical and sociocultural reasons. The comparison of, for example, Mexican and Puerto Rican Spanish with Peninsular Spanish and American dialects of Spanish far removed from immediate Anglophone influences is likely to provide revealing results. Furthermore, future investigations may examine accommodation on other online platforms such as Facebook or Twitter. For instance, we might see how accommodation is performed in messages addressed specifically to one participant, as in dyadic interactions on Twitter, following the research of Danescu et al. (2011).

\section{REFERENCES}

Arguello, J., Butler, B. S., Joyce, E., Kraut, R., Ling, K. S., Rosé, C. \& Wang, X. (2006). Talk to me: Foundations for successful individual-group interactions in online communities. Proceedings of the SIGCHI Conference on Human Factors in Computing Systems (pp. 959-968). New York: ACM Press.

Barak, A., Boniel-Nissim, M. \& Suler, J. (2008). Fostering empowerment in online support groups. Computers in Human Behavior, 24(5), 1867-1883.

Brown, P. \& Levinson, S.C. (1987). Politeness: Some universals in language usage. Cambridge: Cambridge University Press.

Biber, D. \& Finegan, E. (1989). Drift and the evolution of English style: A history of three genres. Language, 65(3), 487-517.

Bunz, U. \& Campbell, S. W. (2004). Politeness accommodation in electronic mail. Communication Research Reports, 21(1), 11-25.

Colley, A., Todd, Z., Bland, M., Holmes, M., Khanom, N. \& Pike, H. (2004). Style and content in e-mails and letters to male and female friends. Journal of Language and Social Psychology, 23(3), 369-378.

Connor, U., Nagelhout, E. \& Rozycki, W. (Eds.) (2008). Contrastive Rhetoric: Reaching to intercultural Rhetoric (Vol. 169). Amsterdam and Philadelphia: John Benjamins.

Crystal, D. (2001). Language and the Internet. Cambridge: Cambridge University Press.

Danescu-Niculescu-Mizil, C., Gamon, M. \& Dumais, S. (2011). Mark my words!: Linguistic style accommodation in social media. Proceedings of the 20th international conference on World Wide Web (pp. 745-754). New York: ACM Press [on line]. Retrieved from: http://arxiv.org/pdf/1105.0673.pdf 
Davison, K. P., Pennebaker, J. W. \& Dickerson, S. S. (2000). Who talks? The social psychology of illness support groups. American Psychologist, 55(2), 205-217.

Eckert, P. \& McConnell-Ginet, S. (2013). Language and gender. Cambridge: Cambridge University Press.

Ferrara, K. (1991). Accommodation in therapy. Contexts of accommodation: Developments in applied sociolinguistics. In H. Giles, N. Coupland \& J. Coupland (Eds.), Contexts of accommodation (pp. 187-222). Cambridge: Cambridge University Press.

Fox, A. B., Bukatko, D., Hallahan, M. \& Crawford, M. (2007). The medium makes a difference: Gender similarities and differences in instant messaging. Journal of Language and Social Psychology, 26(4), 389-397.

Giles, H., Coupland, N. \& Coupland, J. (1991). Accommodation theory: Communication, context. In H. Giles, N. Coupland \& J. Coupland (Eds.), Contexts of accommodation (pp. 1-68). Cambridge: Cambridge University Press.

Giles, H. \& Ogay, T. (2006). Communication accommodation theory. In B. B. Whaley \& W. Samter (Eds.), Explaining Communication: Contemporary Theories and Exemplars (pp. 293-310). Mahwah, NJ: Erlbaum.

Guiller, J. \& Durndell, A. (2006). 'I totally agree with you': Gender interactions in educational online discussion groups. Journal of Computer Assisted Learning, 22(5), 368-381.

Herring, S. C. (2004). Computer-mediated discourse analysis: an approach to researching online communities. In S. A. Barab, R. Kling \& J. H. Gray (Eds.), Designing for Virtual Communities in the Service of Learning (pp. 338-376). Cambridge and New York: Cambridge University Press.

Herring, S. C. \& Stoerger, S. (2014). Gender and (A)nonymity in Computer-Mediated Communication. In S. Ehrlich, M. Mcyerhoff \& J. Holmes (Ed.), The Handbook of Language, Gender, and Sexuality Second Edition (pp. 567-586). New York: John Wiley \& Sons.

Honeycutt, C. \& Herring, S. C. (2009). Beyond microblogging: Conversation and collaboration via Twitter. Proceedings of the Forty-Second Hawai'i International Conference on System Sciences (HICSS-42). Los Alamitos, CA: IEEE Press.

Lakoff, R. (2004). Language and woman's place with annotations by the author. In M. Bucholtz (Ed.), Language and Woman's Place: Text and Commentaries (pp. 16-120). New York: Oxford University Press. 
Lorenzo-Dus, N. \& Bou-Franch, P. (2013). A cross-cultural investigation of email communication in Peninsular Spanish and British English: The role of (in) formality and (in) directness. Pragmatics and Society, 4(1), 1-25.

Machin, D. \& van Leeuwen, T. (2007). Global media discourse: A critical introduction. London and New York: Routledge.

Mo, P. K., Malik, S. H. \& Coulson, N. S. (2009). Gender differences in computermediated communication: A systematic literature review of online healthrelated support groups. Patient Education and Counseling, 75(1), 16-24 [on line]. Retrieved from: http://www.kathrynpieplow.pwrfaculty.org/wpcontent/uploads/2010/01/ge nder_published.pdf

Montero-Fleta, B., Montesinos-López, A., Pérez-Sabater, C. \& Turney, E. (2009). Computer mediated communication and informalization of discourse: The influence of culture and subject matter. Journal of Pragmatics, 41(4), 770-779.

Mulac, A., Studley, L. B., Widenmann, S. \& Bradac, J. J. (1987). Male/female gaze in same-sex and mixed-sex dyads: Gender-linked differences and mutual influence. Human Communication Research, 13, 323-343.

Mur-Dueñas, P. (2007). 'I/we focus on...': A cross-cultural analysis of self-mentions in business management research articles. Journal of English for Academic Purposes, 6(2), 143-162.

Oliveira, S. M. (2013). Address in computer-mediated communication. In S. C. Herring, D. Stein \& T. Virtanen (Eds.). Pragmatics of Computer-Mediated Communication (pp. 291-314). Berlin/Boston: Gruyter Mouton.

Orgad, S. (2006). The cultural dimensions of online communication: A study of breast cancer patients' internet spaces. New Media \& Society, 8(6), 877-899.

Pérez-Sabater, C. (2015). The rhetoric of online support groups: A contrastive analysis English-Spanish. Revista Española de Lingüistica Aplicada, 28(2), 465-485.

Pérez-Sabater, C., Turney, E. \& Montero-Fleta, B. (2008). Orality and literacy, formality and informality in email communication. Ibérica: Revista de la Asociación Europea de Lenguas para Fines Especificos, 15, 71-88.

Pérez-Tellez, F., Cardiff, J., Rosso, P. \& Pinto, D. (2015). Disambiguating company names in microblog text using clustering for online reputation management. Revista Signos. Estudios de Lingüística, 48(87), 54. 
Riordan, M. A., Markman, K. M. \& Stewart, C. O. (2013). Communication accommodation in Instant Messaging: An examination of temporal convergence. Journal of Language and Social Psychology, 32(1), 84-95.

Scissors, L. E., Gill, A. J., Geraghty, K. \& Gergle, D. (2009). CMC we trust: The role of similarity. Proceedings of the SIGCHI Conference on Human Factors in Computing Systems (pp. 527-536). New York: ACM Press [on line]. Retrieved from: http://dgergle.soc.northwestern.edu/resources/ScissorsGillGeraghtyGergle_ SimilarityTrust_CHI2009.pdf

Seale, C., Ziebland, S. \& Charteris-Black, J. (2006). Gender, cancer experience and Internet use: A comparative keyword analysis of interviews and online cancer support groups. Social Science \& Medicine, 62(10), 2577-2590.

Tannen, D. (1991). You just don't understand: Women and men in conversation. New York: William Morrow.

Thomson, R. \& Murachver, T. (2001). Predicting gender from electronic discourse. British Journal of Social Psychology, 40, 193-208.

Werry, C. C. (1996). Internet Relay Chat. In S. C. Herring (Ed), Computer-mediated communication: Linguistic, social and cross-cultural perspectives (pp. 47-63). Amsterdam and Philadelphia: John Benjamins.

White, M. \& Dorman, S. M. (2001). Receiving social support online: Implications for health education. Health education research, 16(6), 693-707.

\section{NOTE}

1 For ethical reasons, excerpts from posts are presented as they appeared on screen but excluding personal information such as names or email addresses. 